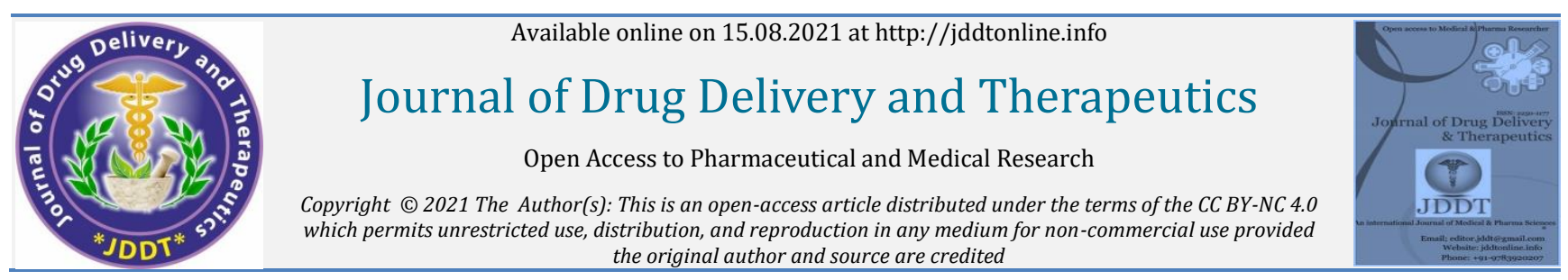

Open Access Full Text Article the original author and source are credited

\title{
The Challenges of Producing Bilayer Tablet: A Review
}

\author{
Abhay Singh*, Sudip Das, Sabnam Gupta, Suman Ghosh \\ Department of Pharmaceutics, Himalayan Pharmacy Institute, Majhitar, Rangpo, Sikkim-737136, India
}

\section{Article Info:}

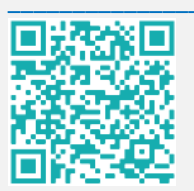

\section{Article History:}

Received 08 June 2021

Reviewed 12 July 2021

Accepted 21 July 2021

Published 15 August 2021

\section{Cite this article as:}

Singh A, Das S, Gupta S, Ghosh S, The Challenges of Producing Bilayer Tablet: A Review, Journal of Drug Delivery and Therapeutics. 2021; 11(4-S):171-175

DOI: http://dx.doi.org/10.22270/jddt.v11i4-S.4922

\section{Abstract}

Bilayer tablets are the advanced form of conventional immediate release tablet system, which consist of either two similar or different drugs combined in a single dose for effective treatment of the disease improving patient compliance. However, the multilayer tablet technology is demanding It also necessitates meticulous selection of excipients and manufacturing conditions for each technological stage. The aim of this review is to provide an outline of state of art of bilayer tablet technology and emphasise the difficulties experienced during Bilayer tablet manufacturing along with its intend solutions for these challenges.

Keyword: Bilayer tablet, Conventional release, Challenges encountered, Compliance.

*Address for Correspondence:

Abhay Singh, Department of Pharmaceutics, Himalayan Pharmacy Institute, Majhitar, Rangpo, Sikkim-737136, India

\section{INTRODUCTION}

Solid oral dosage forms are most favored over other route of drug administration due to ease of drug administration, better patient compliance and flexibility of the design ${ }^{1}$ and still the most extensively used formulation, Almost $90 \%$ of the formulation produced today are consumed orally. It demonstrates that this type of formulation is the most widely accepted globally, and the researcher's primary focus is in this area. Bilayer tablet is a fixed dose combination (FDC) and intended for oral use, it contain immediate release as well as sustained release layer and the immediate release layer deliver the initial dose (loading dose), it contain superdinintegrants that hasten the rate of release of the drug and also attains the onset of action promptly, Whereas sustained release (maintenance dose) layer release the drug in a sustained manner for a prolong period of time by using various polymer acting as a release in retardants, hydrophilic polymer are mostly employed for this sustained release action ${ }^{2}$. Diabetes, antihypertensive, antihistamines, analgesics, antipyretics and antiallergenic agents are mostly suitable for this type of drug delivery ${ }^{3}$. Conventional dosage form causes a broad range of medication concentration fluctuations in the bloodstream and tissues, resulting in unfavorable toxicity and ineffectiveness. As a result of problems including repeated dosage and uncertain absorption, the idea of developing sustained or controlled drug delivery systems was generated. Much more effort is stress out in research and development for successful development of Bilayer system that involves incompatible products, additional equipment and operation challenges 4

\section{CHALLENGES INVOLVED IN MANUFACTURING OF BILAYER TABLET:}

Challenges during the development of bilayer tablets might include inadequate hardness, the order of layer sequence, layer weight ratio, and elastic mismatch of the adjacent layers, first layer tamping force and cross contamination between layers. If these elements are not adequately regulated in some way, they will have an adverse effect on bi-layer compression pressure, as well as qualitative characteristics such as mechanical strength and individual layer weight control. Therefore care must be taken to enable design of a vigorous product and process 5,6 .

Bilayer tablets can be thought of as two single-layer tablets compacted into one but in practicality there are several manufacturing problems associated.

\section{MATERIAL PROPERTIES:}

Physicochemical properties of API and excipients are crucial for the success of Bilayer tablet manufacturing 7, 8. The nature of materials plays a key role in the strength of multilayer tablets and their manner of fracture 9, 10. Material properties such as plasticity, brittleness and visco-elasticity have significant impact on compression process ${ }^{11}$. The plasticity deformation and the brittleness of material have significant role in the compression process. This means that the plasticity would not affect the compression process as long as the elasticity of the plastic material does not go beyond the bond limit. Besides, the particle deterioration in the central area of die is greater in comparison to the outer layer; Hence before using a substance for manufacturing of Bilayer tablets, it's critical to pay attention to its material 
characteristics. 12,13. Each layer in multi-layer tablet formulation must exhibit a sufficient volume reduction and ability to form a mechanically strong and coherent solid form. Therefore, they should be characterized by good compressibility (ability of a substance to reduce the volume under pressure) and compatibility (ability of powdered substances to convert into tablets) ${ }^{14}$. It is important to optimize the size distribution of the particles, the flow characteristics, and compression ability of material when used in layered tablet manufacturing, so as to ensure accurate control of each layer weight.

\section{COMPRESSION FORCE:}

According to the research conducted by the Li et al. ${ }^{15}$, the most vital parameter in the production process of multilayer tablet is the assessment of compression force used for the very first layer, which influences the interfacial strength and adhesion between the two layers, resulting in the mechanical attraction among the layers in the tablet. As a result, if the initial layer of the bilayer medication was more elastic, the stress and tension produced in the entire system as a result of it leads the bilayer tablet's strength to deteriorate. This can cause the bond between the two layers at the bilayer tablet's interface to break which directly impact the adherence of layers 16, 17. The compression pressure and also punch speed significantly affect the compactibility and resistance to compressibility into the die 18. The job of the initial layer of compression forces (generally in the range of $2-18 \mathrm{KN}$ ) is to tamp the powder/granulated substances in order to reduce the volume, smooth the first layer surface and generate a space for depositing the second layer. In general, the application of higher compression force tends to increase tensile strength and decreased surface roughness. Smoothing the surface of the initial layer may augment the delamination by limiting the intermolecular adherence between adjacent layers ${ }^{19}$.

Proper bonding is only obtained when the first layer is compressed at a low compression force so that this layer can still interact with the second layer during final compression of the tablet. Bonding is severely restricted if the first layer is compressed with high compression force.

\section{LUBRICANT:}

Research has showed that substance which is having greater lubricity will have lower friction between its particles and with die when it comes into contact because all the matter will be uniformly distributing. Conversely, when it comes to bilayers substances to achieve greater interaction and strength between the two layers' low lubricant level is obligatory. Because lubricant levels have a greater impact than brittle substances, this characteristic of the material should be considered while dealing with the development of Bilayer tablet. ${ }^{20,21}$

As part of the product development process, the amount of lubricant necessary to avoid picking and sticking of the first layer must be determined. When the granules come into contact with dies and punches during compression, the blended lubricant in the granular bulk spreads throughout the mixture, or "coats" on the surface of the granules, providing lubrication and reducing friction. Lubrication can also diminish inter-granular adhesion, which can have an influence on key quality parameters including tablet breaking force and dissolution. Thus, the influence of lubricant on the essential quality characteristics of the tablet has been studied by adding it to the dies and punches rather than directly to the granules. This procedure is known as external lubrication in the literature. External lubrication, in which the lubricant is sprayed over the die and punches for each compression cycle rather of being added to the bulk powder combination, has been demonstrated to enhance crushing strength by $40 \%$ without extending tablet disintegration time. The presence of a coat of magnesium stearate on the tablet was confirmed using a scanning electron microscope. Though this new technique tends to be beneficial for monolayer tablets, it may be utilized to better understand the influence of lubricant on bilayer tablet quality features.

\section{LAYER RATIO AND LAYER SEQUENCE:}

The least amount of research has been done in this section. In a bilayer tablet, the weight of the two layers is not always the same during the design of bilayer tablets. In majority of cases, there will be a significant variation in the ratio of their weights. However; it has been shown that in most cases, the ratio between the first and second layers might be 1:1, 1:2, or even 1:3 in rare cases. However, making the weight of the second layer constant with that of the first layer, which is typically heavy, is challenging, and this presents a challenge during the creation of bilayer drugs. ${ }^{22,23 .}$

\section{ENVIRONMENTAL CONDITION:}

Environmental condition shall be taken into account while formulating the bilayer tablet, the environmental condition like humidity and moisture have a significant impact on the compactness of bilayer tablets. Despite the fact that only a few authors have looked into the effect of moisture on the strength of bilayer tablets. Bilayer tablet which had been prepared from hygroscopic material will absorb/desorb moisture into/out of their pore structure in response to the relative humidity of the surrounding air.

Furthermore, moisture can penetrate the bulk of the particles if the compacts are composed of starches, microcrystalline cellulose, crospovidone, hydroxypropyl methylcellulose, polyvinylpyrrolidone, sodium starch glycolate, and colloidal silicon dioxide. Layer expansion occurs when moisture is absorbed by porous compacts and/or particles. Any change in layer size weakens the contact between the layers, which might lead to timedependent delamination ${ }^{24}$. It was recommended that the materials be pre-conditioned to ensure that they are in equilibrium with the moisture content of the air in the manufacturing area, and that the compacts be packaged in airtight, moisture-resistant blisters.

Physical stability of bilayer tablets during storage, in addition to formulation design and manufacturing process considerations, is an important factor to consider during product development because it can affect quality attributes such as tensile strength, layer adhesion, friability, and dissolution. The strengths of bilayer tablets made up of plastic/brittle, brittle/plastic and brittle/brittle were compared upon storage. The tablet interfacial strength of bilayer tablets prepared with MCC in the first layer/lactose in the second, and lactose in the first layer/MCC in the second, decreased with increased humidity and storage time, whereas those prepared with lactose/lactose showed an increase in tablet strength due to the formation of solid bridges during storage. ${ }^{25}$

\section{LAYER WEIGHT CONTROL:}

To make sure the content uniformity of the active pharmaceutical ingredients in the bilayer tablets some precursors play a significant role, such as material flow property, particle size distribution, and the ability of the bilayers to press accurately. Each instrumented bilayer press from different vendors has its own weight control 
mechanism. The existing development and commercial presses provide the option of monitoring the first layer weight and the second bilayer weight. However, yet there is no commercially accessible bilayer press with a mechanism to sample the second layer weight independently. This generates a huge challenge while manufacturing the bilayer tablets. Therefore, a way should be developed to minimize this effect 26 .

\section{BILAYER TABLET COMPRESSION MACHINE:}

For formulators and process development scientists working on bilayer tablets, several bilayer presses are commercially available, including Kilian, Oystar Manesty, Hata, Korsch, Courtoy, Fette, Kilian, and Piccola. Most instrumented bilayer presses are equipped with control systems to automatically evaluate compression forces and punch displacements on the presses. Recent advancements in compression machine design and accessories have made it possible to customize features (initial layer sampling, sealed feeders, precompression rolls, layer strain gauge sensitivity and maximum upper punch penetration) to meet the needs of the product. Precompression force, punch velocity, consolidation time, dwell time, and relaxation are all factors to consider. For that reason, Compression machines are critical in the production of bilayer tablets since they can aid in achieving the appropriate dose quality or degrade the tablet's quality. As a result, throughout the development of the bilayer tablet, this region should receive a lot of attention 27,28 .

\section{BILAYER TABLET CHARACTERIZATION:}

It is one of the most important areas which should not be ignored in any case while discussing the bilayer tablets.
While it is theoretically preferable to have a material that can be compressed without deformation and compact on its own when compressed, resulting in a stronger bond between the two layers of a bilayer tablet, there are other factors that influence the formation of the desired quality of bilayer tablets. Particle size distribution, angle of response, photomicroscopic examination, density, compressibility, and moisture sorption capacity are all included in characterization 29,30 .

The following are some of the advantages of bilayer tablet characterization in early formulation development: 31

(i) Determination of the interfacial strength of bilayer tablets using quantitative methods.

(ii) Unusual or severe characteristics of compacted layers must be detected.

(iii) Ensure that the bilayer tablets produced are consistent from batch to batch.

(iv) To create a rationale strategy in order to guide formulation development and the selection of suitable product formulations and manufacturing process.

(v) Explain material failure mechanisms during tablet manufacturing.

(vi) Understand the effect of the factors specific to tableting equipment (e.g., speed of operation, applied forces, etc.).

(vii) Reduction in energy utilization by minimization of faulty tablet production.

(viii) Environmental issues and concerns related to the waste management of materials.

Table 1: Several breakthroughs in the area of bilayer tablets ${ }^{32}$ :

\begin{tabular}{|c|c|c|}
\hline DRUG(s) & DOSAGE FORM & RATIONALE \\
\hline Atorvastatin, Atenolol & Bilayer gastro retentive matrix Tab & Hypertension and hypercholesterolemia treatment \\
\hline Nifedipine & $\begin{array}{l}\text { Gastro retentive floating Bilayer } \\
\text { tablets }\end{array}$ & Hypertension and angina pectoris treatment \\
\hline $\begin{array}{l}\text { Aspirin, } \\
\text { Isosorbide 5-mono-nitrate }\end{array}$ & Sustained Bilayer tablets & Pain, fever, and other inflammatory disorders are treated. \\
\hline Pioglitazone $\mathrm{HCl}$, Gliclazide & Bilayer Tablets & Type II Diabetes Treatment \\
\hline Losartan potassium & Bilayer tablet & Hypertension management \\
\hline $\begin{array}{l}\text { TrimetazidineHCl, } \\
\text { Clopidogrelbisulphate }\end{array}$ & Bilayer tablet & $\begin{array}{l}\text { In the treatment of acute coronary syndromes, } \\
\text { cytoprotective anti-ischemic platelet inhibitors are used. }\end{array}$ \\
\hline Diclofenac, Cyclobenza-prine & Bilayer tablet & In the case of pain, there is a synergistic effect. \\
\hline Granisetron HC1 & Bilayer buccal tablets & $\begin{array}{l}\text { To solve the problem of bioavailability while minimising } \\
\text { adverse effects }\end{array}$ \\
\hline Metformin HC1,Glimipiride & Bilayer tablets & In diabetes, there is a synergistic impact. \\
\hline Indomethacin & Bilayer floating tablets & Drugs are released in two phases. \\
\hline $\begin{array}{l}\text { Metformin HC1, Atorvastatin } \\
\text { Calcium }\end{array}$ & Bilayer tablets & $\begin{array}{l}\text { Polytherapy for the treatment of } \\
\text { hyperlipidemia is being developed. }\end{array}$ \\
\hline $\begin{array}{l}\text { CefiximeTrihydrate, } \\
\text { Dicloxacilline Sodium }\end{array}$ & Bilayer tablets & In bacterial infections, this has a synergistic impact. \\
\hline Piracetam, Vinpocetin & Bilayer tablets & In Alzheimer's disease, there is a synergistic impact. \\
\hline Metformin $\mathrm{HCl}$, Pioglitazone & Bilayer tablets & Diabetes mellitus: a synergistic impact \\
\hline Atenolol & Bilayer buccal tablets & $\begin{array}{l}\text { To address the issue of bioavailability while minimising } \\
\text { adverse effects and administration frequency. }\end{array}$ \\
\hline $\begin{array}{l}\text { Cefuroxime Axetil Potassium } \\
\text { Clavulanate }\end{array}$ & Bilayer tablets & Diabetes mellitus: a synergistic impact \\
\hline $\begin{array}{l}\text { Amlodipine Besilate, } \\
\text { Metoprolol Succinate }\end{array}$ & Bilayer tablets & Hypertension: a synergistic impact \\
\hline $\begin{array}{l}\text { Diclofenac Sodium, } \\
\text { Paracetamol }\end{array}$ & Bilayer tablets & In pain, there is a synergistic effect. \\
\hline Ibuprofen, Methocarba-mol & Bilayer tablets & In case of back pain it has synergistic effect. \\
\hline Atorvastatin Calcium & Bilayer buccal tablets & To solve the bioavailability issue. \\
\hline
\end{tabular}




\section{CONCLUSION}

Bi-layer tablets offer one of the most significant design methods is to combine incompatible drug with various indications and the same drug with varied release rates in a single unit. The bilayer tablet is an upgraded technology that overcomes the limitations of single-layered tablets. Bilayer and monolayer tablet production share several common features of technology as both of these pharmaceutical formulation are prepared by compacting powdered/ granulated API with or without excipients. Multi-layer tablets have many key benefits compared to conventional immediate-release monolayer tablets. Recently, significant advancement in the manufacturing of tablets has been achieved. This has contributed to the improvement of physicochemical properties of tablets, as well as the possibility of producing tablets with modified/controlled release. However, there are nevertheless, a number of technological obstacles need to be overcome in order to achieve a multilayer tablet with parallel levels of reliability as found in monolayer tablets. A key source of design and manufacturing problems of the multilayer tablets is heterogeneity of adjacent layers. Fluctuations of even one of compression parameters (e.g. the compression strength, ratio of the layers, arrangement of layers, the used excipients) can significantly have an effect on the properties of each layer and the interfacial strength. However, considering the different parameters of the manufacturing process of multi-layer tablets, it is possible to attain the desired release profile. Bilayer formulations are convenience dosage form, safe and possess greater advantages to both patient and clinician that it may be administered as a single tablet once a day.

\section{REFERENCES:}

1. Abdul S, Poddar S. A flexible technology for modified release of drugs: multi layered tablets. Journal of Control Release. 2004; 97(3):393-405. https://doi.org/10.1016/S01683659(04)00186-5

2. Yadav G, Bansal M, Thakur N, Khare P. Multilayer tablets and their drug release kinetics for oral controlled drug delivery system, Middle-East Journal of Scientific Research.2013; 16(6):782-795.

3. Reddy P, Rao D, Kumar R. Bi-layer technology-an emerging trend: a review. International Journal of research and development in Pharmacy and Life Sciences. 2013; 2(3):404-411.

4. Rayaprolu M, Junju M K, Voleti V K, Sai P B, Pavani M. A new venture in drug delivery: Bilayer tablets review. International journal of research in pharmaceutical and nano sciences.2013; 2(3):305-316.

5. Patel M, Ganesh N, Tamizh M. Challenges in the formulation of bilayered tablets: a review, International Journal of pharmaceutical research and development.2011; 2(10):30-42.

6. Martindale. The Extra Pharmacopoeia, The Pharmaceutical Press, London, 31st edition, 1996, 936-937.

7. Abebe A, Akseli I, Sprockel O, Kottala N, Cuitino AM. Review of bilayer tablet technology. International Journal of Pharmaceutics.2014; 461(1-2):549-58. https://doi.org/10.1016/j.ijpharm.2013.12.028

8. Busignies V, Mazel V, Diarra H, Tchoreloff P. Role of the elasticity of pharmaceutical materials on the interfacial mechanical strength of bilayer tablets. International Journal of Pharmaceutics. 2013; 457(1):260-67. https://doi.org/10.1016/j.ijpharm.2013.09.009

9. Kottala N, Abebe A, Sprockel O, Bergum J, Nikfar F, Cuitino A M. Evaluation of the performance characteristics of bilayer tablets: Part I. Impact of material properties and process parameters on the strength of bilayer tablets. American association of pharmaceutical scientists, Pharmaceutical Science and
Technology. 2012; 13(4):1236-42.

https://doi.org/10.1208/s12249-012-9845-9

10. Kottala N, Abebe A, Sprockel O, Akseli I, Nikfar F, Cuitino A. Influence of compaction properties and interfacial topography on the performance of bilayer tablets. International Journal of Pharmaceutics. 2012; 436(1-2):171-8.

https://doi.org/10.1016/j.ijpharm.2012.05.026

11. Wu C.Y, Seville J.P. A comparative study of compaction properties of binary and bilayer tablets. Powder Technology. 2009; 189:285-94

https://doi.org/10.1016/j.powtec.2008.04.026

12. Balamuralidhara V, Kumar P T, Srujana N, Venkatesh M, Gupta N V, Krishna K. PH sensitive drug delivery systems: a review, American Journal of drug discovery and development.2011; 1(1):25. https://doi.org/10.3923/ajdd.2011.24.48

13. Wu C Y, Seville J P, A comparative study of compaction properties of binary and bilayer tablets, Powder Technology. 2009; 89(2): 285-294.

https://doi.org/10.1016/j.powtec.2008.04.026

14. Abebe A, Akseli I, Sprockel O, Kottala N, Cuitino A M. Review of bilayer tablet technology. International Journal of Pharmaceutics. 2014; 461(1-2):549-58. https://doi.org/10.1016/j.ijpharm.2013.12.028

15. Li S P, Karth M G, Feld K M, Dipalo L C, Pendaharkar C M, Williams R O. Evaluation of bilayer tablet machines - a case study. Drug Development and Industrial Pharmacy. 1995; 21:571-90. https://doi.org/10.3109/03639049509048124

16. Inman S, Briscoe B, Pitt K.Topographic characterization of cellulose bilayered tablets interfaces, Chemical engineering research and design. 2007; 85 (7): 1005-1012. https://doi.org/10.1205/cherd06188

17. Podczeck F, Muti E.The tensile strength of bilayered tablets made from different grades of microcrystalline cellulose, European Journal of Pharmaceutical Science. 2010; 4 (3):483488. https://doi.org/10.1016/j.ejps.2010.08.002

18. Yang L, Venkatesh G, Fassihi R. Compaction simulator study of a novel triple-layer tablet matrix for industrial tableting. International Journal of Pharmaceutics. 1997; 152:45-52. https://doi.org/10.1016/S0378-5173(97)04911-9

19. Desai D, Wang J, Wen H, Li X, Timmins P. Formulation design, challenges, and development considerations for fixed dose combination (FDC) of oral solid dosage forms. Pharmaceutical development and technology. 2013; 18(6):1265-76. https://doi.org/10.3109/10837450.2012.660699

20. Dietrich P, Bauer-Brandl A, Schubert R, Influence of tableting forces and lubricant concentration on the adhesion strength in complex layer tablets, Drug development and Industrial Pharmacy.2000; 26 (7):745-754. https://doi.org/10.1081/DDC100101293

21. Tye C K, Sun C C, Amidon G E. Evaluation of the effects of tableting speed on the relationships between compaction pressure, tablet tensile strength, and tablet solid fraction, Journal of Pharmaceutical Sciences.2005; 94 (3):465-472. https://doi.org/10.1002/jps.20262

22. Qiu Y, Chidambaram N, Flood K. Design and evaluation of layered diffusional matrices for zero-order sustained-release. Journal of control release. 1998; 51(2-3):123-30. https://doi.org/10.1016/S0168-3659(97)00119-3

23. Maroni A, Zema L, Carea M, Sangalli M.E. Oral pulsatile drug delivery systems. Expert opinion of drug delivery. 2005; 2(5):855-71. https://doi.org/10.1517/17425247.2.5.855

24. Kottala N, Abebe A, Sprockel O. Characterization of interfacial strength of layered powder-compacted solids. Powder Technology.2013; 239:300-307. https://doi.org/10.1016/j.powtec.2012.12.028

25. Jones R.M, 1999. Mechanism of Composite Materials, 2nd ed. Taylor \& Francis, Philadelphia.1999: 245- 246. 
26. Sonar G S, Jain D, More D, Preparation and in vitro evaluation of bilayer and floating-bioadhesive tablets of rosiglitazone maleate, Asian Journal of Pharmaceutical Sciences.2007; 2(4):161-169.

27. Admassu A, Ilgaz A , Omar S , Niranjan K, Alberto M. Review of bilayer tablet technology, International Journal of

Pharmaceutics. 2014; 461: 549-558.

https://doi.org/10.1016/j.ijpharm.2013.12.028

28. Muzzio F J, Lerapetritou M, Portillo P., Llusa M, Levin M. A forward-looking approach to process scale up for solid dose manufacturing, Pharmaceutical Dosage Forms: Tablets. 2008; 3(1):1283-1316.

29. Ankit S, Shashi M K. Bilayer tablet; a promising approach for delivery of dual drugs, International Journal of Physical and Social Science. 2014; 4(9):87-101.
30. Karehill P, Glazer M, Nystrom C. Studies on direct compression of tablets. The importance of surface roughness for the compactability of some directly compressible materials with different bonding and volume reduction properties, International Journal of Pharmaceutics.1990; 64 (1):35-43. https://doi.org/10.1016/0378-5173(90)90176-5

31. Vogeleer J, Smet D. Bilayer tablets - why special technology is required. Pharmaceutical processing. 2002; 1:30-36.

32. Vishwakarma A G, Mogal R T, Pawar A Y. Bilayer Tablet - A New Ways in Oral Drug Delivery System. International Journal of Pharmaceutical Technology and Research, 2014; 6(5):14161428 